\title{
The Differential Effects of High School and Collegiate Student Organization Involvement on Adolescent Leader Development
}

\author{
Dr. David M. Rosch
}

Nicole E. Nelson

\begin{abstract}
We examined the relationship between high school and collegiate organizational involvement and their differential and collective effects on the development of leader selfefficacy, motivation to lead and leadership skill. Our goal was to better understand how the student leader development process unfolds at different points in time over young adulthood. The study investigated members of registered student organizations $(n=757)$ during the Fall 2016 semester. Results of the study indicated strong developmental relationships between past high school involvement, current collegiate involvement and leader capacity change. Positional leadership and students' priority placed on their involvement during high school were predictive of leader skill and self-efficacy, while in college, only mental and physical engagement in organizations predicted leader development.
\end{abstract}

\section{Introduction}

Over half of the youth in the United States aged 6 to 17 have taken part in one or more extracurricular youth organizations (United States Census Bureau, 2014). For those who enter postsecondary education at a traditional age, a similar percentage report participating in one or more organizations (Dugan \& Komives, 2007). One of the core missions of secondary and postsecondary educational institutions is to prepare students so they can be successful in their future careers. Colleges and universities, in particular, have invested in the development of students through traditional curriculum as well as offering opportunities in formal student organizations. At larger universities, many offer opportunities to engage with over 1,000 student organizations, ranging in diverse interests of social, professional, athletic clubs and more (Rosch \& Collins, 2017).

Involvement in extracurricular activities as a youth and young adult have been linked to positive future outcomes in academic achievement and attainment, self-development and community and civic involvement (Barber, Eccles \& Stone, 2001; Marsh, 1988; Eccles \& Barber, 1999; Broh, 2002; Zaff, Moore, Papillo \& Williams, 2003). Involvement in high school has "significantly predicted the outcomes of adolescents" perception towards their leadership skills" (Hancock, Dyk \& Jones, 2012, p. 93). The greatest developmental gains are seen in students that participate in extracurricular activities consistently and when the activities are of varying interests (Fredricks \& Eccles, 2006). However, any level of student involvement, as little as attending a meeting, has been associated with more student development than for those not involved; formally joining and leading an organization predicted increased development even more strongly (Foubert \& Grainger, 2006). The desire to be involved during college has been 
observed in high school students already involved in extracurricular activities (Case, 2011). Given this research, however, we know surprisingly little regarding how the leader development process unfolds across a student's high school and postsecondary education. For example, do high school students learn different lessons regarding their leadership development than they do in college? Are some aspects of leader development more important to learn earlier, where later development in college rests on such earlier learning? The process of adolescent leader development is important to understand, as leadership educators at these levels can better optimize their efforts with a more comprehensive understanding of the needs of their students at each level.

Defining Involvement in Student Organizations. Astin (1984) initially defined student involvement broadly as psychic and physical engagement within the broad milieu within an educational institution - attending and participating in courses, developing formal and informal relationships, creating a physical presence on the campus, etc. For the purposes of this study, we took a more limited view, and follow in the footsteps of an earlier national study on collegiate involvement in student organizations (Foubert \& Grainger, 2006). There, involvement was defined as active physical and psychological engagement in formal student organizations that possess some type of codified relationship with their associated educational institution (high school or collegiate). Examples of involvement, in this context, include attending organizational meetings, participating in formal events, occupying administrative and leadership positions within the organization, and perhaps most broadly, putting time and effort into the work of the organization. Participating in an organization requires a student's time, which is "the most precious institutional resource" according to Astin (1984, p. 522). A student must first have enough time to get involved, and then to put enough time in to reap the benefits of involvement in student organizations. "What a student does in college, rather than who that individual is or the type of institution attended, is the strongest predictor of educational gains" (Dugan, 2013, p. 230; Kuh, Kinzie, Schuh \& Whitt, 2005; Pascarella \& Terenzini, 2005).

\section{Benefits of Formal Involvement.}

In high school. The importance of becoming involved in extracurricular activities and organizations is repeatedly shared with students in high school by counselors, parents, educators and administrators. Becoming involved during high school can have lasting effects on future leadership and personal development. Hancock et al. (2012) found that students' personal perceptions of their leadership capabilities are more pronounced when they participate in extracurricular activities as youth. Eccles and Barber (1999) found that high school involvement "in sports, school-based leadership, schoolspirit activities, and academic clubs predicted increased likelihood of being enrolled fulltime in college at age 21 " (p. 25). High school involvement has also been linked to institutional retention and satisfaction during college (Eccles \& Barber, 1999). Along with retention, better than average academic performance and grade point averages are seen in students that are involved (Broh, 2002; Eccles \& Barber, 1999). Occupying a formal position of leadership also "promotes the development of purpose and a sense that one is on the path to a hopeful future" (Bundick, 2011, p. 70). McFarland and Thomas (2006) found that "involvement in politically salient youth volunteer organizations has significant, positive returns on adult political participation seven to twelve years later" (p. 412). 
In postsecondary education. Collegiate organizational involvement provides some similar benefits to that of high school. Increased academic performance, grades, retention in school and satisfaction with one's educational institution have all been associated with involvement in postsecondary student organizations (Fischer, 2007). For incoming freshman and transfer students, organizations provide a way to integrate into campus life, which could be a factor in increased retention of students (Fischer, 2007). Minority students may especially benefit from their participation; for example, Fischer (2007) found that academic development benefits emerged at greater levels in minority students than in white students. Additionally, involvement in college predicted increased levels of psychological development in first year and senior students (Foubert \& Granger, 2004). These students showed greater levels of "establishing and clarifying purpose, educational involvement, career planning, life management, and cultural participation" (Foubert \& Grainger, 2004, p. 180). Moreover, benefits seem to accrue the deeper the level of involvement. Foubert and Grainger (2006) found that simply attending an organization's meetings were not as beneficial as formally joining or leading within the organization.

Conceptualizing Leader Development. The effect of student experiences on their leader development can be evaluated in many ways. Various models measure the outcomes of leadership development differently, yet many of the overarching ideas overlap. The "Ready, Willing and Able" (RWA) model (Keating, Rosch, \& Burgoon, 2014) places comprehensive leader development within a structure that includes the interactions between students' leader selfefficacy, motivation to lead and leadership skill, respectively. "Ready" refers to one's capacity for leader self-efficacy, or confidence one has that one's actions in a leadership context would be successful. "Willing" refers to the motivations behind taking on leadership responsibilities, or the psychological press students possess to engage in leadership behaviors. Being "Able" refers to one's possession of leadership skill, and therefore optimizing the chances of successfully fulfilling leadership-oriented tasks. Within this model, the outcomes of leader development experiences should be an increase in students' sense of leader self-efficacy, their motivation to engage in leader behaviors, and growth in their leadership-oriented skills. Keating et al. make the argument that, "without any one of these three capacities, leaders may fail to exhibit behaviors necessary for success in organizations" (2014, p. 4).

Although the general benefits of formal involvement are known and widely accepted, there is little research looking at how such involvement in both high school and college differentially contribute to student leader development. It is important to further investigate the effects of involvement so that we can better advise students on the best ways to attain lasting personal and professional success. Previous research has addressed some of these effects, but more needs to be done to understand how high school and collegiate experiences are differentially contributing to leadership development.

\section{Research Design and Question}

This research study was designed to examine the process of how leader development unfolds through formal involvement in high school and collegiate student organizations. We addressed the following overarching research question: To what extent are high school 
organizational involvement and collegiate organizational involvement differentially associated with the ongoing leader development of students who participate within them over time?

\section{Methods}

Population and Sample. Research was conducted during the Fall 2016 semester at a large, highly selective public university in the Midwestern United States. During that semester, the university hosted over 1,400 student organizations incorporating a wide variety of interests. Many of the organizations that participated in this research study were initially contacted at the suggestion of staff within the university office responsible for overseeing formal student organizations - these organizations had healthy relationships with the staff and were, therefore, more likely to respond to an invitation to participate in the project. A smaller group of organizations were associated with the university's college of agriculture, where this study originated, and were more likely to respond to the research invitation than organizations with no association to the study. While these groups do not comprise a random sample, they were still highly diverse in terms of purpose, size, longevity on campus, and organizational structure. Participating organizations included dance organizations, topical interest groups, sport-focused clubs, A Capella groups, fraternities and sororities, and profession-based organizations. While these organizations were by no means fully representative of the broad diversity of student groups that exist on university campuses, they do broadly range in membership, interest, focus, organizational structure, and shape of campus impact. Initial invitation emails were sent to the president (or presiding executive student) of each group within the first month of the fall semester. In total, students within 38 formal student organizations completed the survey, where the mean percentage of completion within each organization was $75 \%$.

Of the 757 individual participants who responded, 65\% identified as a woman $(n=497)$, $31 \%$ as a man $(n=238), 0.1 \%$ as part of the trans* $(n=1)$ community, and $3 \%$ preferred not to identify a gender identity $(n=21)$. Approximately $22 \%$ were freshman $(n=168), 27 \%$ were sophomores $(n=206), 22 \%$ were juniors $(n=164), 21 \%$ were seniors $(n=162)$, and $7 \%$ were graduate students $(\mathrm{n}=55)$. With regards to racial identity, $49 \%$ identified as White $(\mathrm{n}=368), 33 \%$ as Asian American $(n=252), 6 \%$ as Latinx $(n=45), 3 \%$ as African American $(n=19), 1 \%$ as Middle Eastern $(n=8)$ and $3 \%$ preferred not to identify their racial identity or did not respond $(n=23)$. The remaining $6 \%$ of students $(n=42)$ identified as having more than one race or specifically as multiracial.

Variables and Instrumentation. The goal of the study was to determine the differential relationships of various aspects of high school and collegiate involvement to broad-based student leader development. We created a questionnaire that included questions about students' prior high school involvement, their prior and current collegiate involvement, and a popular measure of their leadership capacity. Because high school involvement was measured retrospectively (and for all but freshman, from years ago), we elected to limit our measurement to two general variables - the remembered priority that students placed on being involved in high school student organizations, and whether students occupied a formal position of leadership (executive, committee chair, etc.) at some point during their high school years. To determine the degree to which aspects of collegiate involvement might contribute to leader development, we included survey items assessing as broad a variety of potential roles and behaviors within student 
organizations as typically exist within formal student groups (e.g. "To what extent are you responsible for delegating tasks?" and "To what extent do you attend events coordinated or sponsored by this student organization?"). We attempted to assess less formal aspects of involvement by also requesting that they respond to a survey item assessing the degree to which they are, in general, physically and mentally engaged in their organization.

We included a 28-item instrument to measure leader capacity (Keating et al., 2014). Responses were based on a 7-point Likert scale ranging from "strongly disagree" to "strongly agree." We measured leader self-efficacy by including five items from the Self-Efficacy for Leadership scale (Murphy, 1992). A sample question was "I am confident in my ability to influence a group I lead." We measured motivation to lead by including 16 questions from the Motivation to Lead (MTL) scale (Chan \& Drasgow, 2001). The MTL scale can be broken down into the three subscales of affective-identity (AI), social normative (SN) and non-calculative (NC) motivations to lead (Chan \& Drasgow, 2001). AI assesses a person's self-image as a leader of peers, where an example item from the subscale was "I am the type of person who likes to be in charge of others." SN assesses a person's sense of responsibility to others to lead and includes items like "I feel that I have a duty to lead others if I am asked." The last of the three MTL subcategories, NC, assesses a student's weighing of the costs and personal benefits to taking on a leadership role with regard to the needs of the group, and includes items such as "I would agree to lead others even if there are no special rewards or benefits to that role." Seven items assessing leadership skill were taken from the Podsakoff et al. (1990) Leader Behavior Scale which measures both transformational and transactional leadership capacities. An example item within the scale was "I behave in a manner that is thoughtful to the needs of other group members."

Data Collection. Data were collected over the course of the Fall 2016 semester at organization meetings. Students completed a hard copy survey, while those students that were not in attendance were given the opportunity to complete the survey through an online Qualtrics survey portal. An incentive of $\$ 50$ was awarded to organizations whose total membership participated at a rate of $75 \%$ or greater.

Analytic Design. This research was designed to understand the process of student leader development from high school through college involvement in formal student organizations. We first conducted a frequency analysis of high school engagement levels among the sample of involved college students to determine the degree to which college students were involved in formal organizations in high school. To investigate the degree to which high school and collegiate involvement each contribute to student leadership capacity development, we conducted a series of five two-step hierarchical multiple regressions (one for each sub-scale within the RWA leadership outcomes model), entering high school involvement characteristics in the first step, and collegiate involvement characteristics in the second step to determine the unique contributions of each to the leader development process.

\section{Results}

Our frequency analysis shown in Table 1 reveals the degree to which involved college students reported engagement in high school organizations on a scale from $1=$ no engagement to $4=$ high level of engagement. Almost all of the involved college students $(94.1 \%)$ surveyed rated 
their level of perceived engagement in high school organizations to be moderately engaged or high levels of engagement. In addition, the overall means and standard deviations for each of the RWA capacities can be found in Table 2 .

Table 1

Perceived level of engagement in high school organizations

\begin{tabular}{lll}
\hline & Frequency & Valid Percent \\
\hline No Engagement & 10 & $1.3 \%$ \\
Little Engagement & 34 & $4.6 \%$ \\
Moderate Engagement & 198 & $26.5 \%$ \\
High Level of Engagement & 505 & $67.6 \%$ \\
Total & 747 & $100.0 \%$ \\
\hline
\end{tabular}

Table 2

Mean Scores of Students' Leadership Capacity

\begin{tabular}{lll} 
Measure & $M$ & $S D$ \\
\hline Leadership Self-Efficacy & 5.38 & .843 \\
Affective-identity MTL & 4.89 & 1.07 \\
Social-normative MTL & 5.35 & 1.02 \\
Non-calculative MTL & 5.86 & .882 \\
Transformational \& Transactional Skill & 5.91 & .695 \\
\hline
\end{tabular}

We then examined the degree to which leader development was differentially affected by high school and collegiate involvement. Table 3.1 shows that possessing a high priority to be involved in high school and having held a position in high school emerged as statistically significant $(\mathrm{p}<.05)$, and more powerful predictors (by $\beta$ weight) than any of the collegiate experiences in predicting leader self-efficacy. In the collegiate setting, delegating tasks within the RSO and a student attending events for their organization also emerged as statistically significant predictors $(\mathrm{p}<.05)$ of leader self-efficacy. 
Table 3.1

\begin{tabular}{|c|c|c|c|c|c|c|c|c|}
\hline \multicolumn{9}{|c|}{ Hierarchical Regression of Leader Self-Efficacy $(n=757)$} \\
\hline & \multicolumn{4}{|c|}{ Model 1} & \multicolumn{4}{|c|}{ Model 2} \\
\hline & $B$ & $S E B$ & $\beta$ & $\mathrm{p}$ & $B$ & $S E B$ & $\beta$ & $\mathrm{P}$ \\
\hline (Constant) & 4.217 & .140 & & .000 & 3.442 & .194 & & .000 \\
\hline HS Priority of Involvement & .155 & .044 & .164 & .000 & .148 & .042 & .157 & .000 \\
\hline HS Position of Leadership & .099 & .023 & .195 & .000 & .090 & .023 & .177 & .000 \\
\hline COL Plan Events & & & & & -.007 & .021 & -.019 & .749 \\
\hline COL Attend Meetings & & & & & -.035 & .032 & -.053 & .280 \\
\hline COL Recruit Members & & & & & .013 & .022 & .034 & .543 \\
\hline COL Delegate Tasks & & & & & .059 & .028 & .152 & .037 \\
\hline $\begin{array}{l}\text { COL Make Disciplinary } \\
\text { Decisions }\end{array}$ & & & & & -.007 & .024 & -.017 & .771 \\
\hline COL Attend Events & & & & & .056 & .023 & .119 & .015 \\
\hline COL Attend Service Projects & & & & & .004 & .017 & .011 & .789 \\
\hline COL Advisor Mentorship & & & & & .032 & .018 & .072 & .069 \\
\hline $\begin{array}{l}\text { COL Mentally \& Physically } \\
\text { Engaged }\end{array}$ & & & & & .064 & .033 & .097 & .056 \\
\hline Adjusted $R^{2}$ & \multicolumn{4}{|c|}{.102} & \multicolumn{4}{|c|}{.184} \\
\hline$F$ & \multicolumn{4}{|c|}{39.325} & \multicolumn{4}{|c|}{14.902} \\
\hline$\Delta R^{2}$ & \multicolumn{4}{|c|}{.104} & \multicolumn{4}{|c|}{.093} \\
\hline
\end{tabular}

Elevated levels of affective identity motivation to lead was statistically predicted only by holding a position of leadership in a high school organization (see Table 3.2). This variable was nearly four times more responsible than any other involvement factor in predicting higher levels of affective identity of motivation to lead $(\beta=0.330)$. 
Table 3.2

\begin{tabular}{|c|c|c|c|c|c|c|c|c|}
\hline \multicolumn{9}{|c|}{ Hierarchical Regression of Affective Identity Motivation to Lead ( $n=757)$} \\
\hline & \multicolumn{4}{|c|}{ Model 1} & \multicolumn{4}{|c|}{ Model 2} \\
\hline & $B$ & $S E B$ & $\beta$ & $\mathrm{p}$ & $B$ & $S E B$ & $\beta$ & $\mathrm{p}$ \\
\hline (Constant) & 3.398 & .175 & & .000 & 2.649 & .245 & & .000 \\
\hline HS Priority of Involvement & .070 & .054 & .059 & .194 & .049 & .053 & .041 & .353 \\
\hline HS Position of Leadership & .216 & .029 & .335 & .000 & .213 & .029 & .330 & .000 \\
\hline COL Plan Events & & & & & .040 & .027 & .088 & .143 \\
\hline COL Attend Meetings & & & & & .055 & .041 & .065 & .179 \\
\hline COL Recruit Members & & & & & .007 & .028 & .014 & .801 \\
\hline COL Delegate Tasks & & & & & .023 & .035 & .046 & .522 \\
\hline $\begin{array}{l}\text { COL Make Disciplinary } \\
\text { Decisions }\end{array}$ & & & & & .006 & .030 & .013 & .833 \\
\hline COL Attend Events & & & & & .053 & .029 & .090 & .066 \\
\hline COL Attend Service Projects & & & & & -.006 & .021 & -.012 & .766 \\
\hline COL Advisor Mentorship & & & & & -.031 & .022 & -.054 & .166 \\
\hline $\begin{array}{l}\text { COL Mentally \& Physically } \\
\text { Engaged }\end{array}$ & & & & & .020 & .042 & .024 & .631 \\
\hline Adjusted $R^{2}$ & \multicolumn{4}{|c|}{.137} & \multicolumn{4}{|c|}{.186} \\
\hline$F$ & \multicolumn{4}{|c|}{55.035} & \multicolumn{4}{|c|}{15.088} \\
\hline$\Delta R^{2}$ & \multicolumn{4}{|c|}{.140} & \multicolumn{4}{|c|}{.059} \\
\hline
\end{tabular}

Students who held positions in high school also reported elevated social normative motivation to lead $(\mathrm{p}<.05)$. See Table 3.3. The table also reveals the only collegiate involvement factor associated with elevated social normative motivation to lead was a student's mental and physical engagement in their collegiate student organization. 
Table 3.3

Hierarchical Regression of Social Normative Motivation to Lead

(Constant)

HS Priority of Involvement

\begin{tabular}{cccccccc}
\multicolumn{4}{c}{ Model 1 } & & \multicolumn{4}{c}{ Model 2 } \\
\hline$B$ & SE B & $\beta$ & $\mathrm{p}$ & $B$ & $S E B$ & $\beta$ & $\mathrm{p}$ \\
\hline 4.992 & .146 & & .000 & 3.890 & .201 & & .000 \\
.076 & .045 & .079 & .095 & .062 & .043 & .065 & .151 \\
.103 & .024 & .200 & .000 & .089 & .024 & .173 & .000 \\
& & & & -.012 & .022 & -.032 & .600 \\
& & & & .010 & .033 & .014 & .773 \\
& & & & .023 & .023 & .058 & .307 \\
& & & & .014 & .029 & .035 & .533 \\
& & & & & & & \\
& & & & .001 & .025 & -.002 & .971 \\
& & & & .027 & .017 & .064 & .124 \\
& & & & .000 & .018 & -.001 & .978 \\
& & & & .038 & .035 & .236 & .000
\end{tabular}

HS Position of Leadership

COL Plan Events

COL Attend Meetings

COL Recruit Members

COL Delegate Tasks

COL Make Disciplinary

Decisions

COL Attend Events

COL Attend Service Projects

COL Advisor Mentorship

COL Mentally \& Physically

Engaged

Adjusted $R^{2}$

.063

.150

$F$

23.672

11.928

$\Delta R^{2}$

.065

.099

Elevated levels of non-calculative motivation to lead, however, was associated more with collegiate than high school involvement (see Table 3.4). In particular, being physically and mentally engaged emerged as the most powerful predictor when controlling for all other factors, and the only statistically significant variable other than possessing the priority to be involved in high school. 
Table 3.4

Hierarchical Regression of Non-Calculative Motivation to Lead

(Constant)

HS Priority of Involvement

HS Position of Leadership

COL Plan Events

COL Attend Meetings

COL Recruit Members

COL Delegate Tasks

COL Make Disciplinary

Decisions

COL Attend Events

COL Attend Service Projects

COL Advisor Mentorship

COL Mentally \& Physically

Engaged

Adjusted $R^{2}$

F

$\Delta R^{2}$

\begin{tabular}{|c|c|c|c|c|c|c|c|}
\hline \multicolumn{4}{|c|}{ Model 1} & \multicolumn{4}{|c|}{ Model 2} \\
\hline$B$ & $S E B$ & $\beta$ & $\mathrm{p}$ & $B$ & $S E B$ & $\beta$ & $\mathrm{p}$ \\
\hline 4.513 & .175 & & .000 & 3.600 & .244 & & .000 \\
\hline .156 & .054 & .138 & .004 & .143 & .053 & .126 & .007 \\
\hline .041 & .029 & .067 & .163 & .020 & .029 & .033 & .476 \\
\hline & & & & -.001 & .027 & -.022 & .975 \\
\hline & & & & -.068 & .040 & -.086 & .094 \\
\hline & & & & -.004 & .028 & -.008 & .898 \\
\hline & & & & -.030 & .036 & -.064 & .404 \\
\hline & & & & -.047 & .030 & -.097 & .121 \\
\hline & & & & .039 & .029 & .070 & .171 \\
\hline & & & & .032 & .021 & .064 & .134 \\
\hline & & & & .015 & .022 & .028 & .499 \\
\hline & & & & .225 & .042 & .284 & .000 \\
\hline \multicolumn{4}{|c|}{.032} & \multicolumn{4}{|c|}{.101} \\
\hline \multicolumn{4}{|c|}{12.146} & \multicolumn{4}{|c|}{7.930} \\
\hline \multicolumn{4}{|c|}{.035} & \multicolumn{4}{|c|}{.081} \\
\hline
\end{tabular}

Possessing an elevated level of skill was associated with a variety of high school and collegiate variables (see Table 3.5). Having placed a high priority on being involved in high school, occupying a position of leadership in high school, delegating tasks, attending events, being engaged in general, and possessing a mentor/mentee relationship with the organization's advisor were all positively related to elevated leadership skill. Interestingly, attending collegiate organization meetings negatively predicted the development of leadership skill. 
Table 3.5

\begin{tabular}{|c|c|c|c|c|c|c|c|c|}
\hline \multicolumn{9}{|c|}{ Hierarchical Regression of Leadership Skill } \\
\hline & \multicolumn{4}{|c|}{ Model 1} & \multicolumn{4}{|c|}{ Model 2} \\
\hline & $B$ & $S E B$ & $\beta$ & $\mathrm{p}$ & $B$ & $S E B$ & $\beta$ & $\mathrm{p}$ \\
\hline (Constant) & 5.238 & .119 & & .000 & 4.705 & .165 & & .000 \\
\hline HS Priority of Involvement & .080 & .037 & .103 & .029 & .074 & .036 & .095 & .039 \\
\hline HS Position of Leadership & .064 & .020 & .152 & .001 & .056 & .019 & .134 & .004 \\
\hline COL Plan Events & & & & & .003 & .018 & .010 & .866 \\
\hline COL Attend Meetings & & & & & -.089 & .027 & -.164 & .001 \\
\hline COL Recruit Members & & & & & -.028 & .019 & -.088 & .131 \\
\hline COL Delegate Tasks & & & & & .049 & .024 & .154 & .039 \\
\hline $\begin{array}{l}\text { COL Make Disciplinary } \\
\text { Decisions }\end{array}$ & & & & & -.021 & .020 & -.064 & .294 \\
\hline COL Attend Events & & & & & .044 & .019 & .115 & .023 \\
\hline COL Attend Service Projects & & & & & -.009 & .014 & -.028 & .511 \\
\hline COL Advisor Mentorship & & & & & .033 & .015 & .090 & .027 \\
\hline $\begin{array}{l}\text { COL Mentally \& Physically } \\
\text { Engaged }\end{array}$ & & & & & .128 & .028 & .237 & .000 \\
\hline Adjusted $R^{2}$ & \multicolumn{4}{|c|}{.050} & \multicolumn{4}{|c|}{.123} \\
\hline$F$ & \multicolumn{4}{|c|}{19.047} & \multicolumn{4}{|c|}{9.626} \\
\hline$\Delta R^{2}$ & \multicolumn{4}{|c|}{.053} & \multicolumn{4}{|c|}{.084} \\
\hline
\end{tabular}

\section{Discussion}

The findings of this study suggest that the overwhelming majority of students who were active in collegiate organizations were also involved in high school organizations prior to their postsecondary education. In general, these findings aligned with previous research (e.g. Fredricks \& Eccles, 2006) that suggest consistent involvement in formal student organizations across the young adult years seems to develop leadership capacities in students more strongly than inconsistent or depressed involvement.

Overall, the results seemed to suggest the critical importance of high school involvement in formal organizations in developing future leaders. High school involvement consistently and significantly predicted leader self-efficacy, motivation to lead and the development of leadership skills, and with regard to affective identity motivation to lead, was more than twice as important as collegiate involvement. More specifically, having held a leadership role during high school was the only involvement factor associated with more strongly holding an image of oneself as a leader. This may suggest the powerful role high school organization involvement plays in developing an emerging leader's self-image.

Non-calculative motivation to lead is one's willingness to be a leader even when personal benefits may not outweigh personal costs (Chan \& Drasgow, 2001). It is essentially the motivation to act as a selfless leader. Our results suggested that developing this capacity is most 
related to a felt sense of engagement within one's student organization, whether in high school or college. If students develop commitment to their organizations, these findings unsurprisingly suggest they are more likely to act selflessly in that organization and take on responsibilities that are not explicitly required of them.

The development of leadership skill was associated with both high school and collegiate involvement factors. Presumably, students that place a higher priority on their involvement are going to engage in more opportunities to practice their leadership skills. Conversely, if a student is not committed, they may be less likely to learn the skills necessary to lead. Interestingly, the relationship between students and their advisors only emerged as a significant predictor in the development of skill, not self-efficacy or motivation. According to our results, students increase their chances for skill development when adult advisors mentor them, but these relationships do not necessarily affect their "inner" capacities to lead (i.e. their motivations or self-efficacy).

Surprisingly, most role-specific student organization experiences, such as organizing or planning an event, recruiting members to the organization, making disciplinary decisions, and getting involved in service projects within their organization, held few significant effects on developing a broad-based capacity to lead, when taking into consideration students' commitment to the organization. These findings suggest the degree to which students felt commitment to an organization may be more important than any specific roles or experiences students possess.

Implications. Several implications arise given the results seen within this study. Given the surprising lack of research that integrates high school and collegiate involvement in formal student organizations, these findings may begin to describe common pathways to the development of leadership capacity in adolescence and emerging adulthood. Dugan (2011) suggested that internal states of being related to leadership capacity (specifically, leader selfefficacy) were likely required before leadership skill can be developed. This study provides some degree of support for this assertion, as both leader self-efficacy and affective identity motivation to lead were both more strongly affected by participants' high school experiences, while leadership skill and peer-oriented motivation to lead was more strongly predicted by collegiate factors.

During early adolescence is when many youth develop the identities that they will possess through early adulthood and beyond (Barber, Eccles, \& Stone, 2001). Our results suggest that very few study participants opted to become involved in organizations without first being involved in high school. These findings do not necessarily indicate once a student has graduated from high school that their opportunities for leadership development have been lost. But they suggest that, at least for participants within this study, many pathways to leadership development through formal organizational involvement have closed if they do not start with at least a moderate degree of high school involvement. Moreover, these findings indicate that those responsible for member recruitment in collegiate organizations have not found students who were not already involved in organizations in high school, at least at the university where this study took place.

Another significant implication within this study is the potential that specific roles and behaviors within student organizations may not matter as much as a general commitment to the 
organization. We do not read too deeply into this result - presumably, these roles and behaviors serve as foundational stepping stones in the purposeful practice of leader behaviors - but rather that, without being "physically and mentally committed," simply going through the motions of engaging and leading is not enough to support students' development of leadership capacity.

Those that advise organizations should be ready to assist student members in their leader development. Mentoring received by student organization advisors emerged as one of the more powerful avenues to the development of leadership skill. If the adviser is not readily available to students, members may not receive as many benefits. Moreover, as suggested earlier, developing leader self-efficacy may be an initial stepping stone in developing other aspects of leadership capacity. One way to support such development may be for advisers to create a space that is open and safe for members of the organization to develop socially and in their leadership abilities (Zaff et al., 2003; Kuh 1995). High school educators, in particular, should encourage their students to become active in organizations while in high school. Advisers of these organizations should be encouraged to be liberal with applying titles to roles within the organization (Director of Meeting Icebreakers?), so that students can feel "official" in their participation and invited to deeper levels of commitment.

Future Research. This study was initial and exploratory in examining pathways to leadership development across the broad adolescent period of development. More in-depth research needs to be done to further investigate the relationship between students that get involved during high school and the affect that such involvement has on their development through college and into adulthood. Presumably, the context of this study may skew results. Would findings be similar at less selective, or smaller, or geographically different, or different degree-granting, institutions? Would results look differently if students were surveyed during their high school years, or followed longitudinally, rendering a retrospective design less necessary? Without such study, these results can only be described as initial.

In addition, curious findings emerged relating to the nature of attending meetings in our study. This may have been an outlier, or may indicate the degree to which student organization meetings are poorly run and detrimental to leader development. Given the ubiquity of meetings in formal organizations, more research in this area is necessary.

Conclusion. This study was conducted to determine the relationship between high school and collegiate organization involvement and how these experiences differentially contribute to student leader development. Within this single-campus study, findings suggested a progression of leader development that begins with students in high school developing a sense of leader self-efficacy and a motivation to lead steeped in their own self-image as a leader through being committed to their high school organizations and holding official positions within them. They later continue to develop both of these capacities as well as leadership skill in college, while also deepening their motivation to lead to include peer and organizational factors, regardless of specific roles that they play, as long as they are committed to the organization and its success. While future study is strongly suggested, these findings provide some initial evidence for outlining a common pathway of leader development in adolescence through involvement in formal student organizations. 


\section{References}

Astin, A. W. (1984). Student involvement: A developmental theory for higher education. Journal of College Student Development, 40(5), 518-529.

Barber, B. L., Eccles, J. S., \& Stone, M. R. (2001). Whatever happened to the jock, the brain, and the princess? Young adult pathways linked to adolescent activity involvement and social identity. Journal of Adolescent Research, 16(5), 429-455.

doi:10.1177/0743558401165002.

Broh, B. A. (2002). Linking extracurricular programming to academic achievement: Who benefits and why?. Sociology of Education, 75(1), 69-95. doi:10.2307/3090254.

Bundick, M. J. (2011). Extracurricular activities, positive youth development, and the role of meaningfulness of engagement. The Journal of Positive Psychology, 6(1), 57-74. doi:10.1080/17439760.2010.536775.

Case, K. F. (2011). A gendered perspective on student involvement in collegiate clubs and organizations in Christian higher education. Christian Higher Education, 10(3), 166-195. doi:10.1080/15363759.2011.576208.

Chan, K.-Y., \& Drasgow, F. (2001). Toward a theory of individual differences and leadership: Understanding the motivation to lead. Journal of Applied Psychology, 86(3), 481-498. doi:10.1037//0021-9010.86.3.481.

Dugan, J. P. (2011). Pervasive myths in leadership development: Unpacking constraints on leadership learning. Journal of Leadership Studies, 5(2), 79-84. http://doi.org/10.1002/jls.20223.

Dugan, J. P. (2013). Patterns in group involvement experiences during college: Identifying a taxonomy. Journal of College Student Development, 54(3), 229-246. doi:10.1353/csd.2013.0028.

Dugan, J. P., \& Komives, S. R. (2007). Developing leadership capacity in college students: Findings from a national study. A Report from the Multi-Institutional Study of Leadership. College Park, MD: National Clearinghouse for Leadership Programs.

Eccles, J. S., \& Barber, B. L. (1999). Student council, volunteering, basketball, or marching band: What kind of extracurricular involvement matters?. Journal of Adolescent Research, 14(1), 10-43. doi:10.1207/s1532480xads1003_3.

Fischer, M. J. (2007). Settling into campus life: Differences by race/ethnicity in college involvement and outcomes. The Journal of Higher Education, 78(2), 125-161. doi:10.1353/jhe.2007.0009. 
Foubert, J. D., \& Grainger, L. U. (2006). Effects of involvement in clubs and organizations on the psychosocial development of first-year and senior college students. NASPA Journal, 43(1), 166-182. Doi:10.2202/1949-6605.1576.

Fredricks, J. A., \& Eccles, J. S. (2006). Extracurricular involvement and adolescent adjustment: Impact of duration, number of activities, and breadth of participation. Applied Developmental Science, 10(3), 132-146. doi:10.1207/s1532480xads1003_3.

Hancock, D., Dyk, P. H., \& Jones, K. (2012). Adolescent involvement in extracurricular activities: Influences on leadership skills. Journal of Leadership Education, 11(1), 84101. doi:10.12806/V11/I1/RF5.

Keating, K., Rosch, D., \& Burgoon, L. (2014). Developmental readiness for leadership: The differential effects of leadership courses on creating "ready, willing, and able" leaders. Journal of Leadership Education, 13(3), 1-16. doi:1012806/V13/I3/R1.

Kuh, G. D. (1995). The other curriculum: Out-of-class experiences associated with student learning and personal development. Journal of Higher Education, 66(2), 123-155. doi: $10.2307 / 2943909$.

Kuh, G. D., Kinzie, J., Schuh, J. H., \& Whitt, E. J. (2005). Student success in college: Creating conditions that matter. San Francisco, CA: Jossey-Bass.

Marsh, H. W. (1988). Extracurricular activities: Beneficial extension of the traditional curriculum or a subversion of academic goals?. Journal of Educational Psychology, 84(4), 3-41. doi:10.1037/0022-0663.84.4.553.

McFarland, D. A., \& Thomas, R. J. (2006). Bowling young: How youth voluntary associations influence adult political participation. American Sociological Review, 71, 401-425. doi:10.1177/000312240607100303.

Murphy, S. E. (1992). The contribution of leadership experience and self-efficacy to group performance under evaluation apprehension (Doctoral dissertation). Retrieved from ResearchWorks Archive. (9230410).

Pascarella, E. T., \& Terenzini, P. T. (2005). How college affects students: A third decade of research. San Francisco, CA: Jossey-Bass.

Podsakoff, P. M., MacKenzie, S. B., Moorman, R. H., \& Fetter, R. (1990). Transformational leader behaviors and their effects on followers' trust in leader, satisfaction, and organizational citizenship behaviors. Leadership Quarterly, 1(2), 107-142. doi:10.1016/1048-9843(90)90009-7

Rosch, D.M. \& Collins, J.D. (2017). The significance of student organizations to leadership development. In Rosch, D.M. (Ed.), The role of student organizations in developing leadership (p. 9-19). San Francisco: Jossey-Bass. 
United States Census Bureau. (2014). Nearly 6 Out of 10 Children Participate in Extracurricular Activities, Census Bureau Reports [Press release]. Retrieved December 20, 2016, from http://www.census.gov/newsroom/press-releases/2014/cb14-224.html.

Zaff, J. F., Moore, K. A., Papillo, A. R., \& Williams, S. (2003). Implications of extracurricular activity participation during adolescence on positive outcomes. Journal of Adolescent Research, 18(6), 599-630. doi:10.1177/0743558403254779. 